\title{
Warm nondepolarizing adenosine and lidocaine cardioplegia: Continuous versus intermittent delivery
}

Kathryn L. Sloots, BSc (Hons), ${ }^{a}$ Jakob Vinten-Johansen, PhD, ${ }^{b}$ and Geoffrey P. Dobson, PhD ${ }^{a}$

From the Department of Physiology and Pharmacology, Molecular Science Building, James Cook University, ${ }^{a}$ Townsville, Queensland, Australia; and Cardiothoracic Research Laboratory, Carlyle Fraser Heart Center, Emory University, ${ }^{\mathrm{b}}$ Atlanta, Ga.

Part of the study was supported by the National Heart Foundation of Australia Grant G 05B 2034 (G. P. D.).

Received for publication Oct 20, 2006; revisions received Dec 6, 2006; accepted for publication Dec 18, 2006.

Address for reprints: Geoffrey P. Dobson, $\mathrm{PhD}$, Molecular Science Building, James Cook University, Townsville, Queensland, Australia (E-mail: geoffrey.dobson@jcu. edu.au).

J Thorac Cardiovasc Surg 2007;133:1171-8 $0022-5223 / \$ 32.00$

Copyright $\odot 2007$ by The American Association for Thoracic Surgery

doi:10.1016/j.jtcvs.2006.12.058
Objective: Continuous infusion of warm to normothermic cardioplegia may limit the surgeon's visual field, increase coronary vascular resistance, and lead to potassiumexacerbated ischemia-reperfusion damage. Our aim was to examine the versatility of a new normokalemic, nondepolarizing adenosine-lidocaine cardioplegia during continuous or intermittent infusion at $33^{\circ} \mathrm{C}$ and compare it with lidocaine cardioplegia.

Methods: Isolated, perfused rat hearts ( $\mathrm{n}=6$ each group) were arrested at $33^{\circ} \mathrm{C}$ for 40 or 60 minutes with $200 \mu \mathrm{m}$ of adenosine and $500 \mu \mathrm{m}$ of lidocaine in KrebsHenseleit buffer $\left(10 \mathrm{mmol} / \mathrm{L}\right.$ glucose, $\mathrm{pH} 7.6-7.7$ at $\left.37^{\circ} \mathrm{C}\right)$ or $500 \mu \mathrm{m}$ of lidocaine in Krebs-Henseleit buffer for 60 minutes delivered at $60 \mathrm{~mm} \mathrm{Hg}$.

Results: Times to arrest were 7 to 10 seconds for the adenosine-lidocaine groups and 102 seconds for the lidocaine group $(P<.05)$. Total cardioplegia volumes for intermittent ( 2 minutes every 18 minutes) and continuous deliveries were 122 to 159 $\mathrm{mL}$ and 699 to $922 \mathrm{~mL}$ for the 40- and 60-minute adenosine-lidocaine arrest protocols, respectively, and $136 \mathrm{~mL}$ for the 60 -minute intermittent lidocaine group. In the last 2 minutes of the 40- and 60-minute arrest protocols, the coronary vascular resistance was not significantly different for the hearts arrested with adenosine and lidocaine $\left(0.27-0.32\right.$ megadyne $\left./ \mathrm{sec} / \mathrm{cm}^{-5}\right)$. Significantly higher coronary vascular resistance was found in the lidocaine cardioplegia group $\left(0.38\right.$ megadyne $\left./ \mathrm{sec} / \mathrm{cm}^{-5}\right)$. No significant differences were found between the continuous or intermittent adenosine-lidocaine delivery protocols. Hearts arrested with adenosine and lidocaine recovered $88 \%$ to $89 \%$ of aortic flow and $109 \%$ of coronary flow at 60 minutes of reperfusion after 40 -minute arrest, and $77 \%$ to $86 \%$ of aortic flow and $98 \%$ to $109 \%$ of coronary flow at 60 minutes of reperfusion after 60-minute arrest. Lidocaine cardioplegia led to significantly lower aortic and coronary flows after 60minute arrest compared with the intermittent adenosine-lidocaine group.

Conclusions: We conclude that adenosine-lidocaine cardioplegia can be delivered intermittently or continuously with similar functional recoveries after a 40- or 60 -minute arrest at $33^{\circ} \mathrm{C}$. Hearts receiving lidocaine cardioplegia took a significantly longer time to arrest, showed higher coronary vascular resistance, and achieved lower functional recovery than the 60-minute adenosine-lidocaine cardioplegia groups. Intermittent or continuous delivery of adenosine-lidocaine cardioplegia may offer an alternative to current surgical hyperkalemic cardioplegia at warm to normothermic temperatures.

$\mathrm{F}$ or more than 3 decades, hypothermia has been widely accepted as an important component of myocardial protection during cardiac surgery. ${ }^{1}$ Traditionally, the main reason for selecting hypothermia has been to decrease myocardial oxygen demand beyond the reduction achieved with electrochemical arrest induced by high potassium concentrations. Oxygen consumption during arrest at $11^{\circ} \mathrm{C}$ is $0.135 \mathrm{~mL} \mathrm{O}_{2} / \mathrm{min}$ per $100 \mathrm{~g}$ myocardium $(>97 \%$ reduction from rest at 


\section{Abbreviations and Acronyms}

$\mathrm{AL}=$ adenosine and lidocaine

$\mathrm{CVR}=$ coronary vascular resistance

$37^{\circ} \mathrm{C}$ ) compared with $1.1 \mathrm{~mL} \mathrm{O} /$ min per $100 \mathrm{~g}$ myocardium when arrested at $37^{\circ} \mathrm{C}$ (90\% reduction). ${ }^{2}$ Although hypothermic arrest is still widely used, it has been increasingly associated with myocardial ischemia and stunning. ${ }^{3-5}$ The hypothermic heart, for example, is more susceptible to arrhythmias during "reanimation" and often requires electrical cardioversion to achieve normal sinus rhythm. ${ }^{5}$

In the early- to mid-1980s, Rosenkranz and associates ${ }^{6}$ and Teoh and colleagues ${ }^{7}$ challenged the underlying principles of hypothermic arrest and showed that induction of arrest with normothermic blood cardioplegia was superior to cold blood cardioplegia in functional recovery in the canine model. A few years later, Salerno and colleagues ${ }^{8}$ and Lichtenstein and colleagues ${ }^{9,10}$ proposed warm heart surgery with systemic normothermia as an alternative to hypothermic methods. Studies investigating normothermia have reported improved tissue distribution of oxygen and equivalence or improvement in postischemic functional outcomes, including cognitive functions. ${ }^{5,11-14}$ Nondepolarizing cardioplegia, using lidocaine alone as the arresting agent, has also shown protective properties at normothermic temperatures in animal models. ${ }^{15-17}$

Despite an increasing number of investigators advocating warm surgery, there remain legitimate concerns with cardioplegic arrest at tepid to warm $\left(33^{\circ} \mathrm{C}-37^{\circ} \mathrm{C}\right)$ heart temperatures. One problem confronting surgeons is the fine balance between the need to interrupt cardioplegia delivery to perform surgery and the need to continuously infuse to protect the heart at these higher temperatures. Lichtenstein and others ${ }^{10}$ suggested that a reasonable margin of safety exists if single interruptions are less than approximately 13 minutes. However, the safe period for intermittent delivery and total crossclamp times have not been established. ${ }^{5,10,12,18-20}$ In addition to obscuring the operating field, continuous delivery has been associated with potassium-induced injury to myocytes and the coronary vasculature ${ }^{21}$ increased vascular resistance with prolonged crossclamp times leading to higher pump delivery pressures, ${ }^{22-24}$ and postoperative left ventricular dysfunction. ${ }^{25}$

Accordingly, the aim of the present study was to examine the efficacy of a new normokalemic, nondepolarizing cardioplegia delivered at $33^{\circ} \mathrm{C}$ using both continuous and intermittent delivery protocols in the isolated working rat heart. An arrest temperature of $33^{\circ} \mathrm{C}$ was chosen on the basis of the studies of Engleman and colleagues ${ }^{26}$ and Guyton and colleagues, ${ }^{25}$ who reported that tepid temperatures provided optimal myocardial recovery and brain pro- tection during cardiac surgery. Previously we showed in the rat heart that a crystalloid formulation of adenosine and lidocaine (AL) cardioplegia conferred greater protection at $22^{\circ} \mathrm{C}$ to $29^{\circ} \mathrm{C}$ compared with St Thomas' hospital number 2 solution delivered intermittently during 2 to 4 hours of arrest. ${ }^{27}$ More recently we showed in the canine model of cardiopulmonary bypass that functional recovery after intermittent delivery of normothermic AL blood cardioplegia was equivalent to hypothermic potassium arrest; however, continuous delivery at normothermic temperatures was not studied. ${ }^{28}$ In the present study we report that AL cardioplegia can be delivered continuously or intermittently at $33^{\circ} \mathrm{C}$ with no significant differences in postarrest functional recovery. We also report that lidocaine only cardioplegia was not as effective as AL cardioplegia in the time to arrest maintenance of coronary artery vascular resistance, or functional recovery during reperfusion.

\section{Materials and Methods Animals}

Male Sprague-Dawley rats (370-450 g) from James Cook University's breeding colony were fed ad libitum and housed in a 14:10hour light:dark cycle. Rats were anesthetized with an intraperitoneal injection of thiopentone sodium $(100 \mathrm{mg} / \mathrm{kg}$ body weight), and hearts were rapidly excised. ${ }^{27}$ Rats were handled in compliance with James Cook University Guidelines (Ethics Approval Number A759) and the "Guide for Care and Use of Laboratory Animals," published by the National Institutes of Health (publication 85, revised 1985). Adenosine (A9251 > 99\% purity) and other chemicals were obtained from Sigma Chemical Co (Castle Hill, NSW). Lignocaine hydrochloride (lidocaine) was purchased as a $2 \%$ solution (ilium) from the local Pharmaceutical Supplies (Lyppard, Queensland).

\section{Composition of Buffers and Arrest Solutions}

Krebs-Henseleit perfusion buffer. Isolated rat hearts were perfused in the Langendorff (nonworking) and working mode with a modified Krebs-Henseleit buffer containing $10 \mathrm{mmol} / \mathrm{L}$ glucose; $117 \mathrm{mmol} / \mathrm{L} \mathrm{NaCl}, 5.9 \mathrm{mmol} / \mathrm{L} \mathrm{KCl}, 25 \mathrm{mmol} / \mathrm{L} \mathrm{NaHCO}, 1.2$ $\mathrm{mmol} / \mathrm{L} \mathrm{NaH}{ }_{2} \mathrm{PO}_{4}, 1.12 \mathrm{mmol} / \mathrm{L} \mathrm{CaCl}_{2}\left(\right.$ free $\left.\mathrm{Ca}^{2+}=1.07 \mathrm{mmol} / \mathrm{L}\right)$, $0.512 \mathrm{mmol} / \mathrm{L} \mathrm{MgCl}_{2}$ (free $\mathrm{Mg}^{2+}=0.5 \mathrm{mmol} / \mathrm{L}$ ), pH 7.4 at $37^{\circ} \mathrm{C} .{ }^{27}$ The perfusion buffer was filtered using a $1-\mu \mathrm{m}$ membrane and then bubbled vigorously with $95 \% \mathrm{O}_{2} / 5 \% \mathrm{CO}_{2}$ to achieve a $\mathrm{PO}_{2}$ greater than $600 \mathrm{~mm} \mathrm{Hg}$. The perfusion buffer was not recirculated.

Adenosine and lidocaine arrest solution. Adenosine (200 $\mu \mathrm{m})$ plus lidocaine $(500 \mu \mathrm{m})$ cardioplegia (AL) was freshly prepared in normokalemic Krebs-Henseleit buffer containing 10 $\mathrm{mmol} / \mathrm{L}$ glucose at $\mathrm{pH} 7.7 .{ }^{27}$ The $\mathrm{AL}$ arrest solution was filtered using a $0.2-\mu \mathrm{m}$ filter and delivered at $33^{\circ} \mathrm{C}$. The arrest solution was not actively bubbled with $95 \% \mathrm{O}_{2}$ and $5 \% \mathrm{CO}_{2}$.

Lidocaine arrest solution. Lidocaine $(500 \mu \mathrm{m})$, in an otherwise identical normokalemic Krebs-Henseleit buffer containing $10 \mathrm{mmol} / \mathrm{L}$ glucose, was filtered using a $0.2-\mu \mathrm{m}$ filter and maintained at $33^{\circ} \mathrm{C}$. The arrest solution was not actively bubbled with $95 \% \mathrm{O}_{2}$ and $5 \% \mathrm{CO}_{2}$ 
An adenosine control group was not included in this study because adenosine in Krebs-Henseleit buffer at $200 \mu \mathrm{m}$ does not maintain arrest in the isolated rat heart at $32^{\circ} \mathrm{C}$ to $33^{\circ} \mathrm{C}(\mathrm{n}=2)$ or at $22^{\circ} \mathrm{C}$ to $29^{\circ} \mathrm{C}(\mathrm{n}=6)$ (unpublished data, Sloots, BSc [Hons], 2006).

Isolated-perfused (Langendorff and working) rat heart preparation. Hearts were rapidly removed from anesthetized rats and immediately placed in an ice-cold Krebs-Henseleit buffer. Excess tissue was removed, and the heart was connected through the aorta to a standard Langendorff apparatus and perfused in a retrograde fashion with a perfusion pressure of $80 \mathrm{~cm} \mathrm{H}_{2} \mathrm{O}(60 \mathrm{~mm}$ $\mathrm{Hg}){ }^{27}$ The pulmonary artery was cannulated for collection of coronary venous effluent. After tying off the pulmonary veins and superior and inferior vena cava to minimize leaks $(<1 \mathrm{~mL} / \mathrm{min})$, the atrium was cannulated and the preparation was then switched to working mode. The preload (inflow of buffer into the left atrium) was set at $10 \mathrm{~cm} \mathrm{H}_{2} \mathrm{O}(7.6 \mathrm{~mm} \mathrm{Hg})$, and the afterload was set at $100 \mathrm{~cm} \mathrm{H}_{2} \mathrm{O}(76 \mathrm{~mm} \mathrm{Hg})$. Hearts were stabilized for 10 minutes before converting back to Langendorff (nonworking) mode to administer the arrest solution. Heart rate, aortic pressure, coronary flow, aortic flow, inflow and coronary venous oxygen content, and oxygen consumption were measured before, during, and after arrest as reported previously. ${ }^{27}$ Rate-pressure product, an index of oxygen demand, ${ }^{29}$ was calculated from the heart rate $\times$ peak systolic pressure.

Aortic pressure was measured continuously using a pressure transducer (UFI Instruments, Morro Bay, Calif) coupled to a MacLab 2e (ADI Instruments, Sydney, Australia). Systolic and diastolic pressures and heart rate were calculated from the pressure trace using MacLab software. Inflow and coronary venous perfusate $\mathrm{Po}_{2}$ and $\mathrm{PCO}_{2}, \mathrm{pH}$, and ion concentrations $\left(\mathrm{Ca}^{2+}, \mathrm{Cl}^{-}, \mathrm{K}^{+}\right.$, and $\mathrm{Na}^{+}$) were measured using a Bayer 865 blood gas analyzer (Bayer Diagnostics, Queensland, Australia). Coronary venous flow and aortic flow were measured in volumetric cylinders. The initial criteria for exclusion of working hearts during the 10-minute equilibration period was a heart rate less than 250 beats/min, systolic pressure less than $110 \mathrm{~mm} \mathrm{Hg}$, and coronary flow less than $10 \mathrm{~mL} / \mathrm{min}$. No pacing or cardiac massage was used during the recovery phase in the working mode. The heart's surface temperature was measured during arrest using a Cole-Palmer Thermistor Thermometer (8402-20) (Cole-Palmer Instrument Co, Vernon Hills, Ill), which was tucked under the left auricle.

\section{Mode of Cardioplegic Delivery and Experimental Protocol}

Rats were randomly assigned to 5 groups for delivery of cardioplegia solution: (1) 40-minute arrest with continuous AL solution $(\mathrm{n}=6)$; (2) 40-minute arrest with intermittent AL solution $(\mathrm{n}=$ 6); (3) 60-minute arrest with continuous AL solution $(\mathrm{n}=6)$; (4) 60-minute arrest with intermittent AL solution $(\mathrm{n}=6)$; (5) 60minute arrest with intermittent lidocaine cardioplegia $(n=6)$. Surgical tepid temperature was maintained by placing a thermostatically regulated water-perfused jacket around the heart when required to yield a heart surface temperature of $32^{\circ} \mathrm{C}$ to $33^{\circ} \mathrm{C}$.

\section{Forty-minute Arrest Protocol}

Continuous. The cardioplegia was administered through the aorta at $33^{\circ} \mathrm{C}$ and a constant pressure of $60 \mathrm{~mm} \mathrm{Hg}$ with the heart in the Langendorff mode for 40 minutes. At 18 and 38 minutes the cardioplegia flow rate and volume were measured and used to estimate coronary vascular resistance (CVR) during arrest.

Intermittent. A strategy of 20-minute intervals for delivery of cardioplegia was used. A 50- $\mathrm{mL}$ induction dose of cardioplegia solution was administered at $33^{\circ} \mathrm{C}$, and the aorta was crossclamped using a plastic nontraumatic clip for 18 minutes. The clip was then released to deliver a 2-minute infusion pulse of cardioplegia solution, and the clamp was reapplied. A terminal cardioplegia infusion was given at 38 minutes for 2 minutes. The cardioplegia flow rate and volume at 18 and 38 minutes were measured to estimate CVR.

\section{Sixty-minute Arrest Protocol}

Continuous. The arrest solution was administered in Langendorff mode for 60 minutes per the 40-minute protocol, with cardioplegia volume measured at 18, 38, and 58 minutes of arrest.

Intermittent. A $50-\mathrm{mL}$ induction dose was administered per the 40-minute protocol, with 2-minute pulses of cardioplegia solution at 18 and 38 minutes, and a terminal infusion for 2 minutes after 58 minutes of arrest. The cardioplegia volume at 18, 38, and 58 minutes was measured for estimating CVR.

After arrest, all hearts were switched to working mode and reperfused with oxygenated Krebs-Henseleit buffer containing glucose at $37^{\circ} \mathrm{C}$, and the function was monitored for 1 hour of reperfusion.

\section{Coronary Vascular Resistance}

CVR in megadynes/second/centimeters ${ }^{-5}$ was calculated during cardioplegia delivery by dividing delivery pressure (millimeters of mercury) by flow (milliliters/second) from equation 1 .

$$
C V R=\frac{1333 \times \mathrm{mm} \mathrm{Hg}}{(\mathrm{ml} / \mathrm{sec})} \times 10^{-6}
$$

where $1 \mathrm{~mm} \mathrm{Hg}=1333$ dynes $\mathrm{cm}^{-2}$ and $10^{-6}$ is a conversion factor from dynes to megadynes. ${ }^{27}$

\section{Statistical Analysis}

All results are expressed as mean \pm standard error of the mean. Data from the 40- and 60-minute protocols were analyzed separately. Two-way analysis of variance for repeated measures was used to compare discrete variables (eg, aortic flow, systolic pressures) over multiple time points between the treatment groups, with a Bonferroni post hoc test to show where the differences existed.

\section{Results}

Arrest Times, Cardioplegia Solution Volumes, and Coronary Vascular Resistance

Arrest times are shown in Table 1. No significant differences were found between the different AL arrest protocols, which ranged from $7.2 \pm 0.8$ seconds to $10.0 \pm 1.8$ seconds $(\mathrm{n}=24)$. Hearts receiving lidocaine cardioplegia took $102 \pm 27$ seconds to arrest $(P<.01)$, with values ranging from 25 to 200 seconds (Table 1). In addition, ventricular arrest occurred before atrial arrest in 2 hearts receiving 
TABLE 1. Arrest time and delivered cardioplegia volumes during 40-minute or 60-minute arrest (Langendorff mode) using continuous or intermittent delivery of adenosine and lidocaine or lidocaine only cardioplegia at $32^{\circ} \mathrm{C}$ to $33^{\circ} \mathrm{C}(\mathrm{n}=6$ )

\begin{tabular}{|c|c|c|c|c|c|c|c|c|}
\hline $\begin{array}{l}\text { Cardioplegia delivery } \\
\text { regimen }\end{array}$ & $\begin{array}{l}\text { Arrest time } \\
(\text { (sec) }\end{array}$ & $\begin{array}{c}\text { Induction } \\
\text { volume } \\
\text { (mL) }\end{array}$ & $\begin{array}{c}\text { Cardioplegia } \\
\text { volumes } \\
(2 \mathrm{~min} \text { at } 18 \mathrm{~min}) \\
(\mathrm{mL})\end{array}$ & $\begin{array}{c}\text { Cardioplegia } \\
\text { volumes } \\
\text { (2 min at } 38 \mathrm{~min}) \\
(\mathrm{mL})\end{array}$ & $\begin{array}{c}\text { Cardioplegia } \\
\text { volumes } \\
(2 \mathrm{~min} \text { at } 58 \mathrm{~min}) \\
(\mathrm{mL})\end{array}$ & $\begin{array}{c}\text { Total } \\
\text { cardioplegia } \\
\text { volume }(\mathrm{mL})\end{array}$ & $\begin{array}{l}\text { Time to } \\
\text { first beat } \\
\text { (min) }\end{array}$ & $\begin{array}{l}\text { Time to } \\
\text { aortic flow } \\
\text { (min) }\end{array}$ \\
\hline AL 4 & 0.0 & 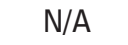 & & & & 699 & 1.7 & \\
\hline AL 40 min intermittent & $8.2 \pm 0.8$ & 50 & .9 & .7 & $\mathrm{~N} / \mathrm{A}$ & $121.5 \pm 0.6$ & $1.8 \pm 0.5$ & $7.5 \pm 1.3$ \\
\hline AL 60 min continuous & $8.0 \pm 0.4$ & $\mathrm{~N} / \mathrm{A}$ & & $30.7 \pm 1.1$ & $0 \pm 1$ & $922.1 \pm 0.3$ & $2.5 \pm 0.2$ & $6.1 \pm 0.7$ \\
\hline AL 60 min intermittent & $7.2 \pm 0.8$ & 50 & $37.3 \pm 2.2$ & $37.0 \pm 2.1$ & $35.3 \pm 2.4$ & $159.3 \pm 0.8$ & $3.5 \pm 0.6$ & $10.0 \pm 2.0$ \\
\hline Lidocaine $60 \mathrm{~min}$ & $102 \pm 27^{*}$ & 50 & $31.7 \pm 2.1$ & $29.0 \pm 2.1$ & $25.5 \pm 1.4 \dagger$ & $136.1 \pm 0.7$ & $3.3 \pm 1.3$ & $11.7 \pm 2.7$ \\
\hline
\end{tabular}

intermittent

$A L$, Adenosine and lidocaine; $N / A$, not available. For methods of the different deliveries see "Materials and Methods." $* P \leq .01$ lidocaine group arrest time with all other groups. $† P \leq .01$ lidocaine group cardioplegia volume at 58 minutes compared with 18 minutes (paired-samples $t$ test), and lidocaine group cardioplegia volume at 58 minutes compared with $\mathrm{AL}$ intermittent group cardioplegia volume at 58 minutes.

lidocaine cardioplegia, and heart escape beats occurred for 2 minutes before full electrochemical arrest was achieved in 1 heart receiving lidocaine.

The total volume of cardioplegia solution delivered to hearts during the 40-minute arrest period was $699.4 \pm 0.5$ $\mathrm{mL}$ during continuous delivery and $121.5 \pm 0.6 \mathrm{~mL}$ during intermittent delivery (Table 1). For the 60-minute arrest protocol, the total cardioplegic volume was $922.1 \pm 0.3 \mathrm{~mL}$ for continuous flow and $159.3 \pm 0.8 \mathrm{~mL}$ for intermittent delivery. There was a slight $(<5 \%)$ decrease in AL cardioplegia volume per minute delivered during the 40- and 60-minute arrest periods, but this was not significant. The volume of lidocaine cardioplegia delivered per minute during the 60-minute arrest period decreased significantly from $31.7 \pm 2.1 \mathrm{~mL} / \mathrm{min}$ to $25.5 \pm 1.4 \mathrm{~mL} / \mathrm{min}(P<.01)$.

CVRs are shown in Figure 1. At 18 minutes of arrest there was no significant difference in CVR between the continuous and the intermittent $\mathrm{AL}$ arrest groups (data not shown), or at 38 minutes $\left(0.28 \pm 0.01\right.$ megadyne $\left./ \mathrm{sec} / \mathrm{cm}^{-5}\right)$ for both 40-minute arrest groups (Figure 1, A), or at 38 minutes for the two 60-minute $\mathrm{AL}$ arrest groups $(0.32 \pm$ 0.01 vs $0.27 \pm 0.02$ megadyne $/ \mathrm{sec} / \mathrm{cm}^{-5}$ (Figure 1, A). Similarly, there was no significant difference at 58 minutes for the continuous and intermittent $\mathrm{AL}$ groups $(0.32 \pm 0.01$ megadyne $/ \mathrm{sec} / \mathrm{cm}^{-5}$ vs $0.27 \pm 0.02$ megadyne $/ \mathrm{sec} / \mathrm{cm}^{-5}$, respectively) (Figure 1, B). In contrast, CVR in the 60minute intermittent lidocaine group was significantly different from the 60-minute intermittent $\mathrm{AL}$ group after 38 minutes of arrest $\left(0.34 \pm 0.03\right.$ megadyne/sec/ $\left.\mathrm{cm}^{-5}\right)(P<$ $.05)$ and during the terminal delivery of cardioplegia after 58 minutes of arrest $\left(0.38 \pm 0.02\right.$ megadyne $\left./ \mathrm{sec} / \mathrm{cm}^{-5}\right)$ $(P<.01)$ (Figure 1, B).

The time for the hearts to spontaneously recover electrical activity after arrest is shown in Table 1 . There were no significant differences between the AL groups or the lidocaine group, although the time to achieve aortic flow varied from $4.0 \pm 0.8$ minutes for the $\mathrm{AL} 40$-minute continuous group to $11.7 \pm 2.7$ minutes for the lidocaine 60 -minute intermittent group. However, this difference was not significant because of the range in data within both the 60-minute intermittent $\mathrm{AL}$ and lidocaine groups (Table 1).

\section{Functional Profiles Before Arrest and During Recovery}

During the pre-arrest period there was no significant difference in the functional parameters measured among the 5 groups tested in the 40- and 60-minute arrest protocols (Tables 2 and 3). Heart rate, developed pressures, aortic flow, coronary flow, and rate-pressure product during the recovery period for the 40-minute arrest groups are shown in Table 2. Percentage recovery of aortic flow and coronary flow during reperfusion are shown in Figure 2, $A$ and $B$. Hearts arrested with continuous AL for 40 minutes recovered $89 \% \pm 6 \%$ of heart rate, $85 \% \pm 5 \%$ of pre-arrest aortic flow, and $100 \% \pm 7 \%$ of pre-arrest coronary flow after 15 minutes of reperfusion. Hearts arrested with intermittent AL for 40 minutes recovered $91 \% \pm 4 \%$ of heart rate, $82 \% \pm$ $3 \%$ of pre-arrest aortic flow, and $106 \% \pm 10 \%$ of pre-arrest coronary flow after 15 minutes of reperfusion. After 30 minutes of reperfusion, the flows had increased to a maximum of $105 \% \pm 7 \%$ of pre-arrest aortic flow and $108 \% \pm$ $4 \%$ of pre-arrest coronary flow in the continuous group, and $94 \% \pm 3 \%$ of pre-arrest aortic flow and $99 \% \pm 3 \%$ of pre-arrest coronary flow in the intermittent group. There was a subsequent slight decrease in aortic flows by 60 minutes of reperfusion, but there was no significant difference in heart rate, aortic flow, coronary flow, or ratepressure product between groups during the recovery period.

Functional parameters during recovery in hearts arrested for 60 minutes are shown in Table 3 and Figure 2, $A$ and $B$. By 15 minutes of reperfusion, heart rate recovered to $82 \% \pm 4 \%$ and $88 \% \pm 5 \%$ of pre-arrest values in hearts arrested with AL continuous and AL intermittent methods, 

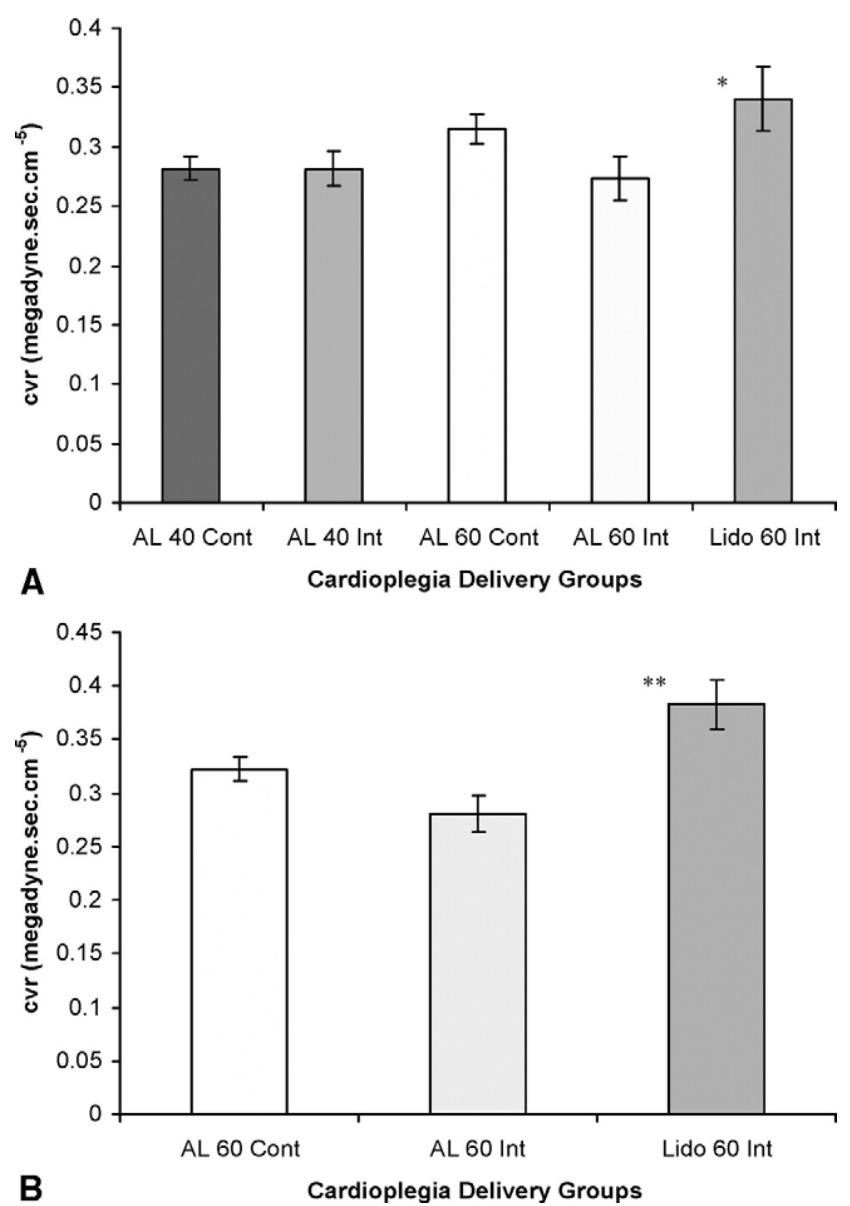

Figure 1. CVR measured after 38-minute arrest (A) and 58-minute arrest (B) in hearts arrested for $\mathbf{4 0}$ or $\mathbf{6 0}$ minutes with continuous or intermittent delivery of AL or lidocaine cardioplegia. $\left({ }^{*} P \leq .05\right.$ lidocaine group compared with $\mathrm{AL}$ intermittent group after 38minute arrest; ${ }^{* * P} \leq .01$ lidocaine group compared with $\mathrm{AL}$ intermittent group after 58-minute arrest.) For the method of CVR calculation, see "Materials and Methods." $A L$, Adenosine and lidocaine; CVR, coronary vascular resistance; Cont, continuous; Int, intermittent.

respectively, and $68 \% \pm 11 \%$ of pre-arrest value in hearts arrested with lidocaine. There were no significant differences between these groups in heart rate or rate-pressure product during the recovery period. After 15 minutes of reperfusion, hearts arrested with AL solution had recovered $77 \% \pm 4 \%$ of pre-arrest aortic flow and $98 \% \pm 5 \%$ of pre-arrest coronary flow in the continuous group and $77 \% \pm$ $7 \%$ of pre-arrest aortic flow and $104 \% \pm 8 \%$ of pre-arrest coronary flow in the intermittent group, compared with $54 \% \pm 12 \%$ recovery of aortic flow and $75 \% \pm 15 \%$ recovery of coronary flow in the lidocaine group. There was a significant difference in recovery of aortic flow between the 60-minute intermittent lidocaine arrest group and the 60-minute intermittent $\mathrm{AL}$ arrest group $(P<.01)$ and $\mathrm{AL}$ continuous group $(P<.05)$. Recovery of coronary flow was also significantly different between the intermittent lidocaine group and the AL intermittent group $(P<.01)$.

When data from AL groups were compared, there was a trend in the intermittent group toward increased coronary flow and lower CVR during arrest, and improved recovery of aortic flow and coronary flow during the recovery period compared with the continuous group, but these differences did not reach statistical significance.

\section{Discussion}

Although hypothermic cardioplegia seems to remain the most popular method of myocardial protection, ${ }^{1,23,30}$ the use of tepid and warm cardioplegia is increasingly being investigated to establish the safe temperature and optimal procedure for protecting the heart and brain during cardiac surgery. ${ }^{13,24,28,31,32}$ The main goal of the present study was to investigate the effect of intermittent delivery of a new normokalemic, nondepolarizing $\mathrm{AL}$ cardioplegia at $33^{\circ} \mathrm{C}$ and compare the results with continuous delivery in the isolated rat heart model. On the basis of functional outcomes (CVR, aortic flow, coronary flow, systolic and diastolic pressures, and heart rate), we report that protection of the myocardium and coronary vasculature seems to be equivalent with intermittent and continuous infusion of $\mathrm{AL}$ cardioplegia during 40 minutes and 60 minutes of arrest at $33^{\circ} \mathrm{C}$. We further report that intermittent delivery of lidocaine cardioplegia was not as effective as intermittent $\mathrm{AL}$ cardioplegia. The presence of adenosine with lidocaine led to faster arrest times and conferred greater protection during and after cardioplegic arrest.

Warm Intermittent Versus Warm Continuous Delivery The present study demonstrated that intermittent AL cardioplegia was equivalent to continuous $\mathrm{AL}$ cardioplegia, despite the fact that total cardioplegia volume for the intermittent group was less than $20 \%$ of the continuous infusion group (Table 1). This shows that greater cardioplegia volume does not improve outcome in this model. In addition, there was no significant difference in CVR between the intermittent and continuous AL groups, with values ranging from $0.27 \pm 0.02$ megadyne $/ \mathrm{sec} / \mathrm{cm}^{-5}$ to $0.32 \pm 0.02$ megadyne/ $\mathrm{sec} / \mathrm{cm}^{-5}$ (Figure 1, $A$ and $B$ ). Changes in CVR may be related to autoregulation (smooth muscle constriction or relaxation), extravascular compression (caused by systolic and diastolic mechanics and tissue edema), or particulate embolization in the microvessels. A relatively constant CVR indicates that there were no differences in smooth muscle reactivity, vascular endothelial function, or extravascular compression from edema during 40 or 60 minutes of global ischemic arrest between the AL groups. In contrast, in pigs undergoing cardiopulmonary bypass, Eric- 
TABLE 2. Functional parameters of isolated rat hearts during pre-arrest and reperfusion (working mode), using continuous or intermittent delivery of adenosine and lidocaine cardioplegia for 40 -minute arrest at $32^{\circ} \mathrm{C}$ to $33^{\circ} \mathrm{C}(\mathrm{n}=6$ )

\begin{tabular}{|c|c|c|c|c|c|c|c|}
\hline Arrest protocol & $\begin{array}{c}\text { 40-minute } \\
\text { cardioplegia } \\
\text { delivery regimen }\end{array}$ & $\begin{array}{l}\text { Heart rate } \\
\text { (beats/min) }\end{array}$ & $\begin{array}{l}\text { Systolic } \\
\text { pressure } \\
(\mathrm{mm} \mathrm{Hg})\end{array}$ & $\begin{array}{l}\text { Diastolic } \\
\text { pressure } \\
(\mathrm{mm} \mathrm{Hg})\end{array}$ & $\begin{array}{c}\text { Aortic flow } \\
\text { (mL/min) }\end{array}$ & $\begin{array}{l}\text { Coronary } \\
\text { flow } \\
\text { (mL/min) }\end{array}$ & $\begin{array}{c}\text { Rate pressure } \\
\text { product } \\
\text { (mm Hg/min) }\end{array}$ \\
\hline \multirow[t]{2}{*}{ Pre-arrest } & Continuous & $297 \pm 18$ & $140.8 \pm 0.8$ & $65.0 \pm 3.4$ & $60.3 \pm 0.5$ & $20.8 \pm 1.2$ & $41,733 \pm 2339$ \\
\hline & Intermittent & $313 \pm 16$ & $136.7 \pm 3.1$ & $63.3 \pm 2.1$ & $57.7 \pm 2.9$ & $19.2 \pm 1.0$ & $42,700 \pm 1835$ \\
\hline \multirow[t]{2}{*}{ Reperfusion 15 min } & Continuous & $263 \pm 20$ & $140.0 \pm 2.2$ & $65.0 \pm 2.6$ & $51.3 \pm 2.9$ & $20.8 \pm 1.9$ & $36,600 \pm 2623$ \\
\hline & Intermittent & $282 \pm 11$ & $133.3 \pm 6.3$ & $61.7 \pm 4.0$ & $47.8 \pm 3.9$ & $20.0 \pm 1.5$ & $37,425 \pm 1799$ \\
\hline \multirow[t]{2}{*}{ Reperfusion $30 \mathrm{~min}$} & Continuous & $281 \pm 15$ & $137.5 \pm 2.1$ & $65.8 \pm 3.3$ & $53.8 \pm 1.1$ & $22.3 \pm 1.2$ & $38,513 \pm 1713$ \\
\hline & Intermittent & $321 \pm 14$ & $127.5 \pm 5.3$ & $63.3 \pm 4.0$ & $54.0 \pm 1.9$ & $19.0 \pm 1.3$ & $40,783 \pm 2013$ \\
\hline \multirow[t]{2}{*}{ Reperfusion 45 min } & Continuous & $300 \pm 17$ & $133.3 \pm 2.5$ & $65.0 \pm 3.4$ & $54.2 \pm 0.4$ & $23.2 \pm 1.2$ & $39,913 \pm 1940$ \\
\hline & Intermittent & $325 \pm 12$ & $126.7 \pm 5.1$ & $65.0 \pm 5.0$ & $52.8 \pm 1.8$ & $21.0 \pm 1.7$ & $41,021 \pm 1658$ \\
\hline \multirow[t]{2}{*}{ Reperfusion $60 \mathrm{~min}$} & Continuous & $306 \pm 13$ & $133.3 \pm 2.5$ & $65.0 \pm 3.4$ & $53.3 \pm 0.7$ & $22.7 \pm 0.9$ & $40,729 \pm 1594$ \\
\hline & Intermittent & $322 \pm 8$ & $127.5 \pm 4.6$ & $66.0 \pm 4.9$ & $51.0 \pm 1.7$ & $20.7 \pm 0.9$ & $40,958 \pm 1607$ \\
\hline
\end{tabular}

sson and colleagues ${ }^{23}$ demonstrated that CVR increased 1.7 times from approximately $0.33 \mathrm{~mm} \mathrm{Hg} / \mathrm{min} / \mathrm{mL}^{-1}$ at 5 minutes to $0.55 \mathrm{~mm} \mathrm{Hg} / \mathrm{min} / \mathrm{mL}^{-1}$ at 45 minutes; they suggested that this increase may have been linked to increased endothelial dysfunction or perivascular edema associated with warm continuous hyperkalemic cardioplegia. We did not test vascular reactivity for endothelial function and therefore cannot comment on potential differences in endothelial function between the groups. Using a canine model, Torchiana and colleagues ${ }^{24}$ demonstrated that CVR increased slowly to a maximum of 2.5 -fold in the last minute of receiving antegrade warm hyperkalemic blood cardioplegia. They and others further postulated that the increased CVR was likely caused by the depolarizing potassium in the cardioplegia, an observation previously noted by Kucich in $1987,{ }^{22}$ and that this effect of potassium may be more pronounced at higher temperatures. ${ }^{33,34}$ Furthermore, in 1991 Mankad and colleagues ${ }^{21}$ reported that high potassium levels in St Thomas' hospital solution or Bretschneider solution resulted in endothelial damage and that this deleterious effect of potassium was concentration dependent. Increased CVR during arrest from hyperkalemia may also compromise the distribution of the cardioplegic solution and increase the risk of ischemic injury. ${ }^{23}$ For

TABLE 3. Functional parameters of isolated rat hearts during pre-arrest and reperfusion (working mode), using continuous or intermittent delivery of adenosine and lidocaine or lidocaine only cardioplegia for 60 -minute arrest at $32^{\circ} \mathrm{C}$ to $33^{\circ} \mathrm{C}$ $(n=6)$

\begin{tabular}{|c|c|c|c|c|c|c|c|}
\hline Arrest protocol & $\begin{array}{c}\text { 60-minute } \\
\text { cardioplegia } \\
\text { delivery regimen }\end{array}$ & $\begin{array}{c}\text { Heart } \\
\text { rate } \\
\text { (beats/min) }\end{array}$ & $\begin{array}{l}\text { Systolic } \\
\text { pressure } \\
(\mathrm{mm} \mathrm{Hg})\end{array}$ & $\begin{array}{l}\text { Diastolic } \\
\text { pressure } \\
(\mathrm{mm} \mathrm{Hg})\end{array}$ & $\begin{array}{c}\text { Aortic } \\
\text { flow } \\
\text { (mL/min) }\end{array}$ & $\begin{array}{l}\text { Coronary } \\
\text { flow } \\
\text { (mL/min) }\end{array}$ & $\begin{array}{c}\text { Rate pressure } \\
\text { product } \\
\text { (mm } \mathrm{Hg} / \mathrm{min})\end{array}$ \\
\hline \multirow[t]{3}{*}{ Pre-arrest } & AL continuous & $309 \pm 10$ & $126.7 \pm 3.6$ & $71.7 \pm 4.0$ & $56.7 \pm 1.6$ & $20.7 \pm 0.8$ & $39,025 \pm 892$ \\
\hline & AL intermittent & $317 \pm 14$ & $140.0 \pm 3.9$ & $75.0 \pm 3.2$ & $61.0 \pm 2.4$ & $21.3 \pm 1.7$ & $44,275 \pm 2155$ \\
\hline & Lidocaine intermittent & $339 \pm 16$ & $134.2 \pm 2.7$ & $70.0 \pm 2.2$ & $51.7 \pm 0.8$ & $19.8 \pm 1.4$ & $45,413 \pm 1949$ \\
\hline \multirow[t]{3}{*}{ Reperfusion 15 min } & AL continuous & $254 \pm 17$ & $126.7 \pm 4.2$ & $72.5 \pm 4.4$ & $44.0 \pm 3.1$ & $20.3 \pm 1.7$ & $31,875 \pm 1295$ \\
\hline & AL intermittent & $276 \pm 12$ & $135.0 \pm 3.4$ & $75.8 \pm 2.7$ & $46.8 \pm 4.3$ & $22.2 \pm 2.3$ & $37,292 \pm 2124$ \\
\hline & Lidocaine intermittent & $226 \pm 34$ & $124.3 \pm 14.0$ & $70.0 \pm 5.0$ & $27.5 \pm 6.2$ & $14.2 \pm 2.8$ & $30,327 \pm 5526$ \\
\hline \multirow[t]{3}{*}{ Reperfusion 30 min } & AL continuous & $288 \pm 14$ & $122.5 \pm 4.6$ & $74.2 \pm 4.0$ & $47.8 \pm 2.5$ & $20.7 \pm 1.1$ & $34,938 \pm 966$ \\
\hline & AL intermittent & $304 \pm 6$ & $132.5 \pm 3.6$ & $76.7 \pm 2.5$ & $54.3 \pm 2.1$ & $20.7 \pm 1.1$ & $40,271 \pm 1179$ \\
\hline & Lidocaine intermittent & $293 \pm 17$ & $127.5 \pm 1.7$ & $72.5 \pm 3.1$ & $37.2 \pm 2.5$ & $16.2 \pm 0.9$ & $37,329 \pm 2242$ \\
\hline \multirow[t]{3}{*}{ Reperfusion $45 \mathrm{~min}$} & AL continuous & $297 \pm 18$ & $120.8 \pm 4.5$ & $73.3 \pm 4.4$ & $46.3 \pm 2.7$ & $21.0 \pm 1.8$ & $35,496 \pm 1331$ \\
\hline & AL intermittent & $310 \pm 10$ & $132.5 \pm 4.2$ & $75.8 \pm 3.3$ & $53.5 \pm 2.0$ & $22.8 \pm 1.2$ & $40,929 \pm 1041$ \\
\hline & Lidocaine intermittent & $290 \pm 13$ & $126.7 \pm 1.7$ & $71.7 \pm 2.8$ & $37.5 \pm 1.9$ & $16.3 \pm 0.9$ & $36,817 \pm 2042$ \\
\hline \multirow[t]{3}{*}{ Reperfusion 60 min } & AL continuous & $297 \pm 16$ & $119.2 \pm 4.4$ & $73.3 \pm 4.4$ & $43.5 \pm 3.6$ & $20.5 \pm 1.9$ & $35,008 \pm 826$ \\
\hline & AL intermittent & $317 \pm 12$ & $132.5 \pm 4.2$ & $76.7 \pm 2.5$ & $52.6 \pm 1.9$ & $23.0 \pm 1.1$ & $41,854 \pm 1538$ \\
\hline & Lidocaine intermittent & $302 \pm 13$ & $124.2 \pm 1.5$ & $70.8 \pm 2.7$ & $36.3 \pm 2.2^{*}$ & $16.8 \pm 0.7 \dagger$ & $37,513 \pm 1946$ \\
\hline
\end{tabular}

$A L$, Adenosine and lidocaine. *Significant difference in aortic flow between lidocaine intermittent group compared with $\mathrm{AL}$ intermittent group $(P \leq .01)$ and $\mathrm{AL}$ continuous group $(P \leq .05)$. $†$ Significant difference in coronary flow between lidocaine intermittent group compared with $\mathrm{AL}$ intermittent group $(P \leq .01)$. 

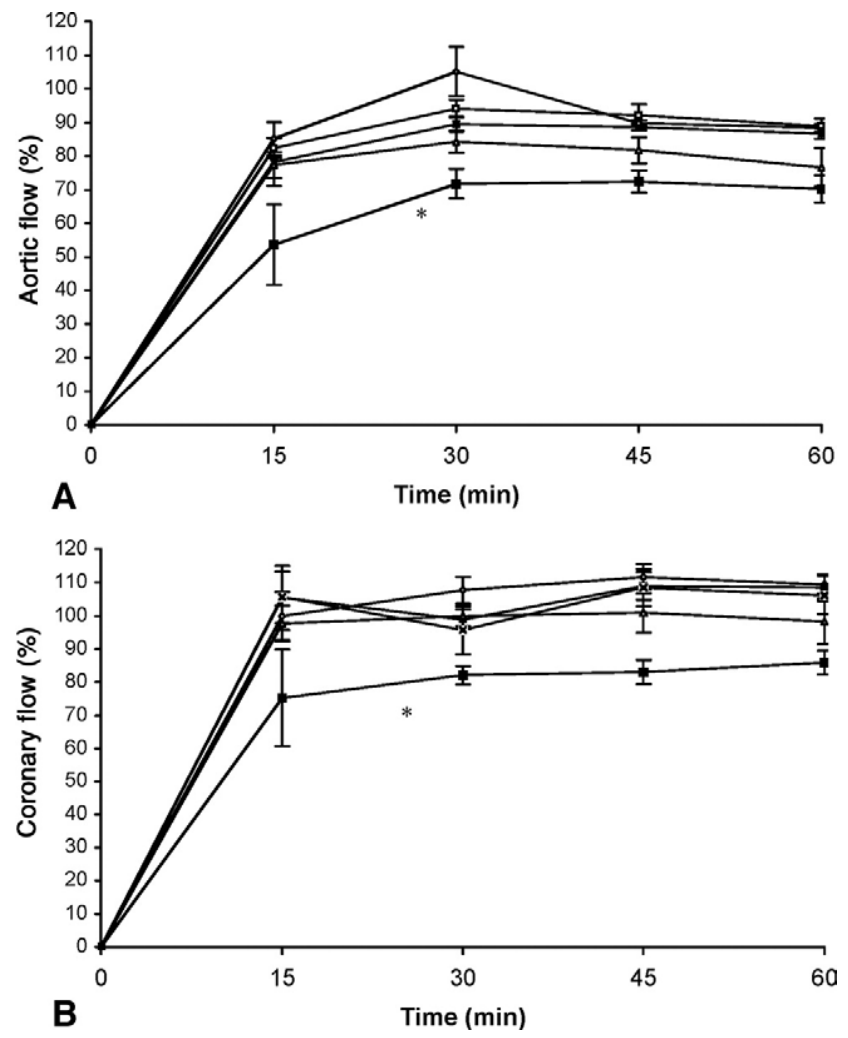

Figure 2. Percentage of pre-arrest values of $(A)$ aortic flow and (B) coronary flow recorded during the 60-minute reperfusion period in hearts arrested with $\diamond: 40$ minutes of continuous $A L, \square$ : 40 minutes of intermittent $A L, x$ : 60 minutes of continuous $A L, \Delta$ : 60 minutes of intermittent $A L$, and $\square$ : 60 minutes of intermittent lidocaine. *Significant difference in aortic flow between the 60-minute intermittent lidocaine group compared with 60-minute $A L$ intermittent group $(P \leq .01)$ and 60 -minute $A L$ continuous group $(P \leq .05)$, and *significant difference in coronary flow between the 60-minute intermittent lidocaine group compared with 60-minute $\mathrm{AL}$ intermittent group $(P \leq .01)$.

many decades, high depolarizing potassium concentrations have been used in aortic ring studies and artery conduits to induce maximum vasoconstriction response when studying the effect of new drugs on coronary vasoreactivity. ${ }^{35} \mathrm{AL}$ cardioplegia may offer an alternative to the possible detrimental effects of high depolarizing potassium concentration on the microvasculature because potassium is kept at normal plasma values. ${ }^{27}$

After global ischemic arrest, our study also showed that there were no significant differences in functional recovery after 40- and 60-minute arrest with AL (Tables 2 and 3). For example, hearts arrested for 60 minutes with intermittent or continuous AL recovered similar percentages of pre-arrest values in developed pressures, heart rate, aortic flow, coronary flow, and rate-pressure product after 60 minutes of reperfusion (Table 3). These data suggest that the myocardium and coronary microvasculature were protected during the 40- or 60-minute arrest period using AL cardioplegia at $33^{\circ} \mathrm{C}$. Although there was a trend for intermittent delivery of AL cardioplegia to improve functional recovery after 60 minutes of arrest, these differences were not significant.

\section{Warm Intermittent Adenosine-Lidocaine Cardioplegia Versus Lidocaine Cardioplegia}

Intermittent AL cardioplegia was also compared with intermittent lidocaine cardioplegia over a 60-minute arrest at $33^{\circ} \mathrm{C}$. In this study, intermittent lidocaine cardioplegia was not as effective as intermittent AL cardioplegia, with variable and significantly longer arrest times (102 \pm 27 seconds vs $7.2 \pm 0.8$ to $10.0 \pm 1.8$ seconds) (Table 1 ), significantly higher CVR during arrest $(\sim 20 \%$ higher CVR measured at 38 and 58 minutes) (Figure 1, B), and significantly lower returns in aortic and coronary flows during reperfusion $(P<$ .01) (Table 3). Lidocaine cardioplegia has been advocated as an alternative to $\mathrm{K}^{+}$depolarizing cardioplegia by a number of groups using Langendorff perfused rat and rabbit hearts. ${ }^{15-17}$ Although lidocaine at $500 \mu \mathrm{m}$ arrests the rat heart faster than does clamping a heart receiving KrebsHenseleit alone $(1.7 \pm 0.45$ vs $10.7 \pm 2.2$ minutes $(n=4$, unpublished data, Sloots, BSc [Hons], 2006), the key is to include $200 \mu \mathrm{m}$ of adenosine, which arrests the heart faster and confers greater protection on the myocardium and coronary vasculature compared with lidocaine only cardioplegia (Figure 1, $B$; Table 3).

\section{Conclusions}

In the past, surgeons have been reluctant to adopt warm cardiac surgery presumably because of the effects of near-continuous delivery of depolarizing potassium cardioplegia on the heart and the potential deleterious effects of higher temperatures on brain function. ${ }^{5,10,19,20}$ In addition, there seems to be a lack of consensus concerning the safe period for interrupting the flow of cardioplegia to visualize the operative field and the length of crossclamp time. ${ }^{5,10,19,20}$ The possible clinical significance of developing nondepolarizing AL cardioplegia may relate to (1) reducing the need for high depolarizing potassium in cardioplegia; (2) offering the surgeon greater versatility over the visual field at higher temperatures; (3) providing lower CVR and greater uniformity of cardioplegia delivery to the myocardium; (4) protecting the myocardium and coronary vasculature from ischemic injury ${ }^{36-38}$; (5) providing greater control over the patient's serum $\mathrm{K}^{+}$levels and other related electrolytes, particularly in those patients with renal disease; and (6) having the benefits of potent anti-inflammatory properties. ${ }^{18,39,40} \mathrm{Al}$ though we acknowledge the strengths and limitations of using the perfused rat heart model and crystalloid cardioplegia in this study, ${ }^{41}$ further large animal studies and human safety trials are required to examine AL cardioplegia as an alternative to conventional $\mathrm{K}^{+}$-based cardioplegia practices. 


\section{References}

1. Flack JE, Cook JR, May SJ, Lemeshow S, Engelman RM, Rousou JA, et al. Does cardioplegia type affect outcome and survival in patients with advanced left ventricular dysfunction.? Results from CABG Patch Trial. Circulation. 2000;102:84-9.

2. Buckberg GD. Myocardial protection: an overview. Semin Thorac Cardiovasc Surg. 1993;5:98-106.

3. Mezzetti A, Calafiore AM, Lapenna D, Deslauriers R, Ganghong T, Salerno TA, et al. Intermittent antegrade warm cardioplegia reduces oxidative stress and improves metabolism of the ischaemic-reperfused human myocardium. J Thorac Cardiovasc Surg. 1995;109:785-95.

4. Torracca L, Pasini E, Curello S, Ceconi C, Coletti G, Alfieri O, et al. Continuous versus intermittent warm blood cardioplegia: functional and energetics changes. Ann Thorac Surg. 1996;62:1172-8; discussion $1178-9$.

5. Gaillard D, Bical O, Paumier D, Trivin F. A review of myocardial normothermia: its theoretical basis and the potential clinical benefits in cardiac surgery. Cardiovasc Surg. 2000;8:198-203.

6. Rosenkranz ER, Vinten-Johansen J, Buckberg GD, Okamoto F, Edwards $\mathrm{H}$, Bugyi $\mathrm{H}$. Benefits of normothermic induction of blood cardioplegia in energy-depleted hearts, with maintenance of arrest by multidose cold blood cardioplegic infusions. J Thorac Cardiovasc Surg. 1982;84:667-77.

7. Teoh KH, Christakis GT, Weisel RD, Fremes SE, Mickle DA, Romaschin $\mathrm{AD}$, et al. Accelerated myocardial metabolic recovery with terminal warm blood cardioplegia. J Thorac Cardiovasc Surg. 1986; 91:888-95

8. Salerno TA, Houck JP, Barrozo CA, Panos A, Christakis GT, Abel JG, et al. Retrograde continuous warm blood cardioplegia: a new concept in myocardial protection. Ann Thorac Surg. 1991;51:245-7.

9. Lichtenstein SV, Ashe KA, el Dalati H, Cusimano RJ, Panos A, Slutsky AS. Warm heart surgery. J Thorac Cardiovasc Surg. 1991; 101:269-74.

10. Lichtenstein SV, Naylor CD, Feindel CM, Sykora K, Abel JG, Slutsky AS, et al. Intermittent warm blood cardioplegia. Warm Heart Investigators. Circulation. 1995;92:II341-6.

11. Randomised trial of normothermic versus hypothermic coronary bypass surgery. The Warm Heart Investigators. Lancet. 1994;343:559-63.

12. Calafiore AM, Teodori G, Bosco G, Di Giammarco G, Vitolla G, Fino $\mathrm{C}$, et al. Intermittent antegrade warm blood cardioplegia in aortic valve replacement. J Card Surg. 1996;11:348-54.

13. Tan TE, Ahmed S, Paterson HS. Intermittent tepid blood cardioplegia improves clinical outcome. Asian Cardiovasc Thorac Ann. 2003;11: 116-21.

14. Tulner SA, Klautz RJ, Engbers FH, Bax JJ, Baan J, van der Wall EE, et al. Left ventricular function and chronotropic responses after normothermic cardiopulmonary bypass with intermittent antegrade warm blood cardioplegia in patients undergoing coronary artery bypass grafting. Eur J Cardiothorac Surg. 2005;27:599-605. Epub 2005 Jan 6.

15. Sunamori M, Shimizu M, Tabuchi N, Arai H, Tanaka H. The use of nondepolarising cardioplegic solution for cardiac preservation has a beneficial effect on the left ventricular diastolic function. Transpl Int. 2001;14:72-9.

16. Chambers DJ, Hearse DJ. Cardioplegia and surgical ischaemia. In: Sperelakis N, Kurachi Y, Terzic A, Cohen MV, eds. Heart Physiology and Pathophysiology. San Diego: Academic Press; 2001:887-926.

17. Watanabe M, Egi K, Shimizu M, Nakahara H, Tanaka H, Sakamoto T, et al. Non-depolarizing cardioplegia activates Ca2+-ATPase in sarcoplasmic reticulum after reperfusion. Eur J Cardiothorac Surg. 2002; 22:951-6.

18. Matsuura H, Lazar HL, Yang XM, Rivers S, Treanor PR. Detrimental effects of interrupting warm blood cardioplegia during coronary revascularisation. J Thorac Cardiovasc Surg. 1993;106:357-61.

19. Tonz M, Krogmann ON, Hess OM, Leskosek B, Mihaljevic T, von Segesser LK, et al. Effect of intermittent warm blood cardioplegia on functional recovery after prolonged cardiac arrest. Ann Thorac Surg. 1996;62:1146-51.
20. de Oliveira NC, Boeve TJ, Torchiana DF, Kantor HL, Titus JS, Schmidt CJ, et al. Ischemic intervals during warm blood cardioplegia in the canine heart evaluated by phosphorus 31-magnetic resonance spectroscopy. J Thorac Cardiovasc Surg. 1997;114:1070-9.

21. Mankad PS, Chester AH, Yacoub MH. Role of potassium concentration in cardioplegic solutions in mediating endothelial damage. Ann Thorac Surg. 1991;51:89-93.

22. Kucich VA, Ilbawi MN, DeLeon SY, Idriss FS, Paul MH, Lehne RM. Factors influencing coronary vascular resistance during hypothermia. J Surg Res. 1987;42:394-401.

23. Ericsson AB, Takeshima S, Vaage J. Warm or cold continuous blood cardioplegia provides similar myocardial protection. Ann Thorac Surg. 1999;68:454-9.

24. Torchiana DF, Vine AJ, Titus JS, Hahn C, Shebani KO, Geffin GA, et al. The temperature dependence of cardioplegic distribution in the canine heart. Ann Thorac Surg. 2000;70:614-20.

25. Guyton RA, Gott JP, Brown WM, Craver JM. Cold and warm myocardial protection techniques. Adv Card Surg. 1996;7:1-29.

26. Engleman RM, Pleet AB, Rousou JA, Flack JE, Deaton DW, Gregory $\mathrm{CA}$, et al. What is the best perfusion temperatures for coronary revasularisation? J Thorac Cardiovasc Surg. 1996;112:1622-33.

27. Dobson GP, Jones MW. Adenosine and lignocaine: a new concept in non-depolarising surgical arrest, protection and preservation. $J$ Thorac Cardiovasc Surg. 2004;127:794-805.

28. Corvera JS, Kin H, Dobson GP, Kerendi F, Halkos ME, Katzmark S, et al. Polarized arrest with warm or cold adenosine/lidocaine blood cardioplegia is equivalent to hypothermic potassium blood cardioplegia. J Thorac Cardiovasc Surg. 2005;129:599-606.

29. Rooke GA, Feigl EO. Work as a correlate of canine left ventricular oxygen consumption, and the problem of catecholamine oxygen wasting. Circ Res. 1982;50:273-86.

30. Louagie YA, Jamart J, Gonzalez M, Collard E, Broka S, Galanti L, et al. Continuous cold blood cardioplegia improves myocardial protection: a prospective randomized study. Ann Thorac Surg. 2004;77:664-71.

31. Fiore AC, Swartz MT, Nevett R, Vieth PJ, Magrath RA, Sherrick A, et al. Intermittent antegrade tepid versus cold blood cardioplegia in elective myocardial revascularization. Ann Thorac Surg. 1998;65: 1559-64.

32. Franke UF, Korsch S, Wittwer T, Albes JM, Wippermann J, Kaluza M, et al. Intermittent antegrade warm myocardial protection compared to intermittent cold blood cardioplegia in elective coronary surgery-do we have to change? Eur J Cardiothorac Surg. 2003;23:341-6.

33. Rosenfeldt FL, Conyers AJ, Jabolnski P, Langley L, Richards SM, Self $\mathrm{G}$, et al. Comparison of UW solution and St Thomas solution in the rat: importance of potassium concentration. Ann Thorac Surg. 1996;61: 576-84.

34. Ou R, Gavin JB, Esmore DS, Rosenfeldt FL. Increased temperature reduces the protective effect of university of Wisconsin solution in the heart. Ann Thorac Surg. 1999;68:1628-34.

35. Chong WC, Ong PJ, Hayward C, Moat N, Collins P. Effects of storage solutions on in vitro vasoreactivity of radial artery conduits. $J$ Thorac Cardiovasc Surg. 2001;122:470-5.

36. Canyon SJ, Dobson GP. Protection against ventricular arrhythmias and cardiac death using adenosine and lidocaine during regional ischemia in the in vivo rat. Am J Physiol (Heart Circ Physiol). 2004;287: H1286-95.

37. Canyon SJ, Dobson GP. Pretreatment with an adenosine A1 receptor agonist and lidocaine: a possible alternative to myocardial preconditioning. J Thorac Cardiovasc Surg. 2005;130:371-7.

38. Canyon SJ, Dobson GP. The effect of adenosine and lidocaine infusion on myocardial high energy phosphates and $\mathrm{pH}$ during regional ischemia in the rat model in vivo. Can J Physiol Pharmacol. 2006;84:903-12.

39. Vinten-Johansen J. Involvement of neutrophils in the pathogenesis of lethal myocardial reperfusion injury. Cardiovasc Res. 2004;61:481-97.

40. Cassuto J, Sinclair R, Bonderovic M. Anti-inflammatory properties of local anesthetics and their present and potential clinical implications. Acta Anaesthesiol Scand. 2006;50:265-82.

41. Sutherland FJ, Hearse DJ. The isolated blood and perfusion fluid perfused heart. Pharmacol Res. 2000;41:613-27. 